\title{
Examining the Psychometric Properties of Acceptance Scale for Kindergarten-Revised (ASK-R) in Turkish
}

\author{
Deniz Tekin Ersan ${ }^{1}$, Seda Ata ${ }^{1}$, Sinem Kaya ${ }^{1}$ \\ ${ }^{1}$ Mugla Sitki Kocman University, Turkey \\ Correspondence: Seda Ata, Mugla Sitki Kocman University, Turkey.
}

Received: January 6, 2017

doi:10.11114/jets.v5i5.2129

\author{
Accepted: March 19, 2017 \\ Online Published: April 5, 2017 \\ URL: https://doi.org/10.11114/jets.v5i5.2129
}

\begin{abstract}
The aim of this study is to investigate the applicability of ASK-R among Turkish pre-school children and determine the psychometric properties (validity and reliability) of this scale. This study was conducted with 167 students from different pre-schools in Muğla. Within the aim of the study, three different methods were set down in order to investigate the validity of the scale. First of all, in order to get evidences about the construct validity of the scale, item analysis was conducted. In order to examine construct validity, confirmatory factor analysis was conducted. The fit statistics obtained from factor analysis showed that original form's factor structure had been confirmed. Internal consistency was calculated and Cronbach's alpha coefficient for the total scale was high. The test-retest correlation coefficient for the total score were significant $(\mathrm{r}=.78, \mathrm{p}<0.01)$. As a result of the study, the Turkish version of ASK-R has good validity and reliability for Turkish pre-school children.
\end{abstract}

Keywords: acceptance, early childhood, inclusion, scale, special education

\section{Introduction}

Peer acceptance plays important role on children's school adjustment (Ladd, Kochenderfer \& Coleman, 1997). Young children's peer acceptance affects many aspects of their development and wellbeing such as their academic and socioemotional achievement (Buhs \& Ladd, 2001). Children with special needs in inclusive settings also affected by social acceptance (Bossaert, Colpin, Pijl \& Petry, 2013). In order to result with successful inclusion, not only placing a child with special needs in an inclusive class but also social acceptance should be considered. Children with special needs may be informed and prepared for the class but rest of the class determine social interaction and peer acceptance. In inclusive settings, children need support for building acceptance (Ostrosky, Mouzourou, Dorsey, Favazza \& Leboeuf, 2015). Especially in early childhood, these interventions even needed more because it is known that the younger children have more peer victimization behaviors towards children with special needs (Vreeman \& Carroll, 2007). Children at this age group think that they can not play with their peers who have special needs. Therefore, children with special needs engage in less social integration with their peers (Odom, 2000). Building acceptance among children in their early years may take more effort. There should be interventions to prevent the rejection of children with special needs in early childhood (Ostrosky, et.al., 2015).

Inclusive classrooms should be assessed for acceptance in order to determine their needs for support and also for determine effectiveness of interventions (Favazza, Phillipsen \& Kumar, 2000). A variety of methods such as questionnaires, interviews, sociometric peer ratings, and behavioral observations can be used for assessing young children's attitudes toward peers with special needs (Yu, Ostrosky \& Fowler, 2012). Scales are one of the most useful and empirical methods for measuring children's attitudes and acceptance levels towards their peers with special needs (Vignes, Coley, Grandjean, Godeau \& Arnaud, 2008). Favazza, Phillipsen, and Kumar's (2000) Acceptance Scale for Kindergartners- Revised (ASK-R) is one of the well-known and practical assessment scale for measuring acceptance in classrooms consist of young children. It has been used in researches both in Western (Boer, Pijl, Minnaert, \& Post, 2014; Nikolaraizi, Kumar, Favazza, Sideridis, Koulousiou \& Riall, 2005) and Eastern cultures (Oh, 2016).

In Turkey, with the recent policies of inclusive education, children with special needs integration is increased in mainstream schools in the early childhood (Diken, Rakap, Diken, Tomris \& Celik, 2016). Although Turkey is moving forward in policies, service-delivering has still challenges. Social awareness must be increased immediately in early childhood and early childhood special education. Turkey is in a great need of tested interventions and qualified service 
providers. Adapting and generating new and valid assessment tools considered as one of the priorities in early childhood interventions and early childhood special education (Diken, et.al, 2012).

On inclusion, most of the studies in Turkey interested in teachers' and parents' views, attitudes (Metin, 2016). In few studies, attitudes and social acceptance of children without special needs in inclusive classrooms were studied (Aktaş \& Küçüker, 2002; Şahbaz, 2007). All participants in these studies were older children in K-5. No study was found which examines children's acceptance level in early childhood. In the light of the literature, the aim of this study is to investigate psychometric properties of ASK-R amongst pre-school students. With this aim, factor structure, item-total correlations, internal consistency and test-retest reliability were examined for ASK-R Turkish form.

\section{Method}

\subsection{Study Group}

The group of the research is consisted of 167 pre-school children. Children were selected from the pre-schools in the city center of Muğla. Children generally come from medium SES level. 41.9\% (70 children) of the children are girls and $58.1 \%$ (97 children) of them are boys. The age range of the sample is between 59-87 months (Mean: 72.33, sd: 7.69). 127 (76\%) participants of the study group have an inclusive student in their own classroom and 40 (24\%) have not.

\subsection{Acceptance Scale for Kindergarten-Revised (ASK-R)}

The Acceptance Scale for Kindergarten- Revised examined by Favazza and Odom (1999). The ASK-R is a 18-item and 3 -point scale (yes $=2$ point, maybe $=1$ point, no $=0$ point). Items reflect acceptance levels of children with disabilities or children who are different. An example of an item is "Would you play with a kid if he had a disability?". Cronbach alpha coefficient of orijinal ASK-R is reported as .87 and a Spearman-Brown split half is reported as .91.

\subsection{Translation ASK-R into Turkish and Pilot Study}

The translation studies of ASK-R were designed as a serial approach as Herrera, Delcampo \& Ames (1993) suggest. First, ASK-R was translated from English to Turkish by four experts working in the different departments of Faculty of Education (Department of Preschool Education, Department of Special Education and Department of Guidance and Counseling). Then, all translation texts are evaluated together for the community sample. Later on, back translation studies were also done and after all editing, the last Turkish form of ASK-R was composed. Lastly, Turkish form of ASK-R were asked to five experts if the items of Turkish form is consisted with the original form, or not. All experts' opinions are considered and items of Turkish form were revised according to these opinions.

Before the data collection process, pilot studies were performed to 5 children to understand if the items are clear for Turkish culture and language. Furthermore, last changes were done to the scale by experiments of applicator of the pilot group.

During the pilot studies, administrators realized that children had difficulty answering some items (16 and 18), which have low correlations with other items. Some children were even irritated while answering these questions and also had feelings of being accused. Therefore these items were excluded from the main analysis. Also item 2 was excluded due to low factor loading (factor loading <.30). This exclusions result final scale of 15 items for Turkish form.

\subsection{Process}

Before the application of the tools, all the participants' parents were asked if they want their children to be a participant of the research by fulfilling an informed consent form. The children, whose parents accept to participate the research, were applied data collection tool by applicants. Applicants were 4th grade college students and trained by researchers about the application process. Two weeks of training covered basic test application techniques for children, observations, trials and one by one supervisions.

\subsection{Administrations}

Although Favazza and Odom (1999) recommended group administration and children marked themselves if children have preschool experience and familiar of taking tests, during the pilot study it is seen that children effect each other's' answers and test took relatively longer. Test material has not been changed but marking was not done by children. The questionnaire was printed on colored sheets including three faces which are "sad", "happy" and "maybe" faces for each item. All children took ASK-r individually in their own schools. Personal data forms were fulfilled by children's teachers by looking through personal files. Each application took approximately 15 minutes. Applications took place in an empty classroom or schools' resource rooms which were quiet spaces without distractions and interruptions. There were two university students during the application. One was administering ASK-r and other student stand behind the child and camera only the administrative's face. This was a precaution and videos were reviewed by researchers whether if test application is correct or not. Two university students collect their observational data together after the test. 
Lisrel 8.9 and SPSS 17.00 were used to analyze the data. Confirmatory factor analysis, item-total statistics, test-retest reliability and internal consistency test were conducted to investigate psychological properties of ASK-R.

\section{Results}

\subsection{Adaptation to Turkish Process}

There were difficulties regarding the translation of the ASK-r from English language into Turkish language due to differences between these two languages. In order to adapt ASK-r accurately, some of the words were modified from the original version. Modifications were made according to the comments made by the experts and data obtained in the pilot testing. There were also changes because of the cultural factors. Especially in the training questions in the white page, one of the question has been changed completely in order to get a "yes" answer.

\subsection{Descriptive Statistics of ASK-R Turkish Form}

The sample of the study consists of 167 pre-school children. Participants' minimum score is 2 and their maximum score is 30. Sample's mean for ASK-R Turkish form is 17.19, standard deviation is 7.76. Table 1 shows the answers of the participants for each item.

Table 1. Frequences of the Answers for the ASK-R Turkish Form

\begin{tabular}{llll}
\hline Item & Yes (f/\%) & No $(\mathbf{f} / \%)$ & Maybe (f/\%) \\
\hline Item 1 & $76(45.5 \%)$ & $86(51.5 \%)$ & $5(3 \%)$ \\
Item 3 & $98(58.7 \%)$ & $65(38.9)$ & $4(2.4 \%)$ \\
Item 4 & $120(71.9 \%)$ & $40(24.0 \%)$ & $7(4.2 \%)$ \\
Item 5 & $102(61.1 \%)$ & $59(35.3 \%)$ & $6(3.6 \%)$ \\
Item 6 & $103(61.7 \%)$ & $60(35.9 \%)$ & $4(2.4 \%)$ \\
Item 7 & $44(26.3 \%)$ & $119(71.3)$ & $4(2.4 \%)$ \\
Item 8 & $121(72.5 \%)$ & $38(22.8 \%)$ & $8(4.8 \%)$ \\
Item 9 & $111(66.5 \%)$ & $51(30.5 \%)$ & $5(3 . \%)$ \\
Item 10 & $25(15.0 \%)$ & $142(85 \%)$ & $0(0 \%)$ \\
Item 11 & $165(98.8 \%)$ & $2(1.2 \%)$ & $0(0 \%)$ \\
Item 12 & $93(55.7 \%)$ & $64(38.3 \%)$ & $10(6.0 \%)$ \\
Item 13 & $40(24 \%)$ & $121(72.5 \%)$ & $6(3.6 \%)$ \\
Item 14 & $116(69.5 \%)$ & $48(28.7 \%)$ & $3(1.8 \%)$ \\
Item 15 & $104(62.3 \%)$ & $59(35.3 \%)$ & $4(2.4 \%)$ \\
Item 17 & $81(48.5 \%)$ & $80(47.9 \%)$ & $6(3.6)$ \\
\hline
\end{tabular}

\subsection{Item Total Statistics}

Reliability of the ASK-R Turkish Form was assessed by testing the internal consistency of each items. Table 2 shows the correlations between all items. As can be seen on the table, internal consistency of items' coefficients range between .32 and .77 . This results reveal that reliability of ASK-R's Turkish Form is quite satisfactory.

Table 2. Item-Total Statistics

\begin{tabular}{lllll}
\hline Item & Scale Mean if Item Deleted & Scale Variance if Item Deleted & Corrected Item-Total Correlation & Cronbach's Alpha if Item Deleted \\
\hline Item1 & 61.50 & 237.43 & .63 & .73 \\
Item3 & 61.25 & 241.86 & .49 & .73 \\
Item4 & 60.97 & 243.53 & .50 & .73 \\
Item5 & 61.19 & 239.27 & .59 & .73 \\
Item6 & 61.19 & 234.75 & .74 & .72 \\
Item7 & 61.89 & 246.58 & .37 & .74 \\
Item8 & 60.95 & 241.78 & .57 & .73 \\
Item9 & 61.08 & 235.01 & .77 & .72 \\
Item10 & 62.14 & 249.70 & .32 & .74 \\
Item11 & 60.93 & 248.52 & .34 & .74 \\
Item12 & 61.27 & 234.75 & .74 & .72 \\
Item13 & 61.93 & 247.66 & .30 & .74 \\
Item14 & 61.04 & 248.06 & .77 & .74 \\
Item15 & 61.17 & 234.18 & .68 & .72 \\
Item17 & 61.44 & 235.83 & & .72 \\
\hline
\end{tabular}

\subsection{Factor Validity}

Multivariate tests of normality revealed evidence of marked positive skew and curtisos in the data. Therefore, the data has deviations from normality, therefore examining confirmatory factor analysis Robust Maksimum Likelihood method and Lisrel 8.0 program were used (Jöreskog \& Sorbom, 1993). There has been much discussion in the literature over what represents good model fit. We identified the following criteria to indicate good model fit: relative chi-square $(\chi 2 / \mathrm{df})<3$, 
CFI $\geq .90$, GFI $\geq .90$, RMSEA $<.08$, and NFI $\geq .95$ (Hooper, Coughlin, \& Mullen, 2008; Ullman, 2001). In this study, chi-square test was found non-significant, suggesting that there were no discrepancies between the relationships observed variables and variables which implied by the hypothesised one-factor model.

Confirmatory factor analysis applied and in the first model, a one factor model was tested as suggested in the original form. Fit indices for tested model were $\left(\chi^{2}=182.99 ; \mathrm{df}=90 ; \mathrm{CFI}=.974 ; \mathrm{NFI}=.950 ; \mathrm{IFI}=.974\right.$; RMSEA=0.078) "good" for the current sample and The confirmatory factor analysis results of ASK-R. All indicators at the recommended criterion levels were satisfied.

Table 3. Standardized factor loadings on the items

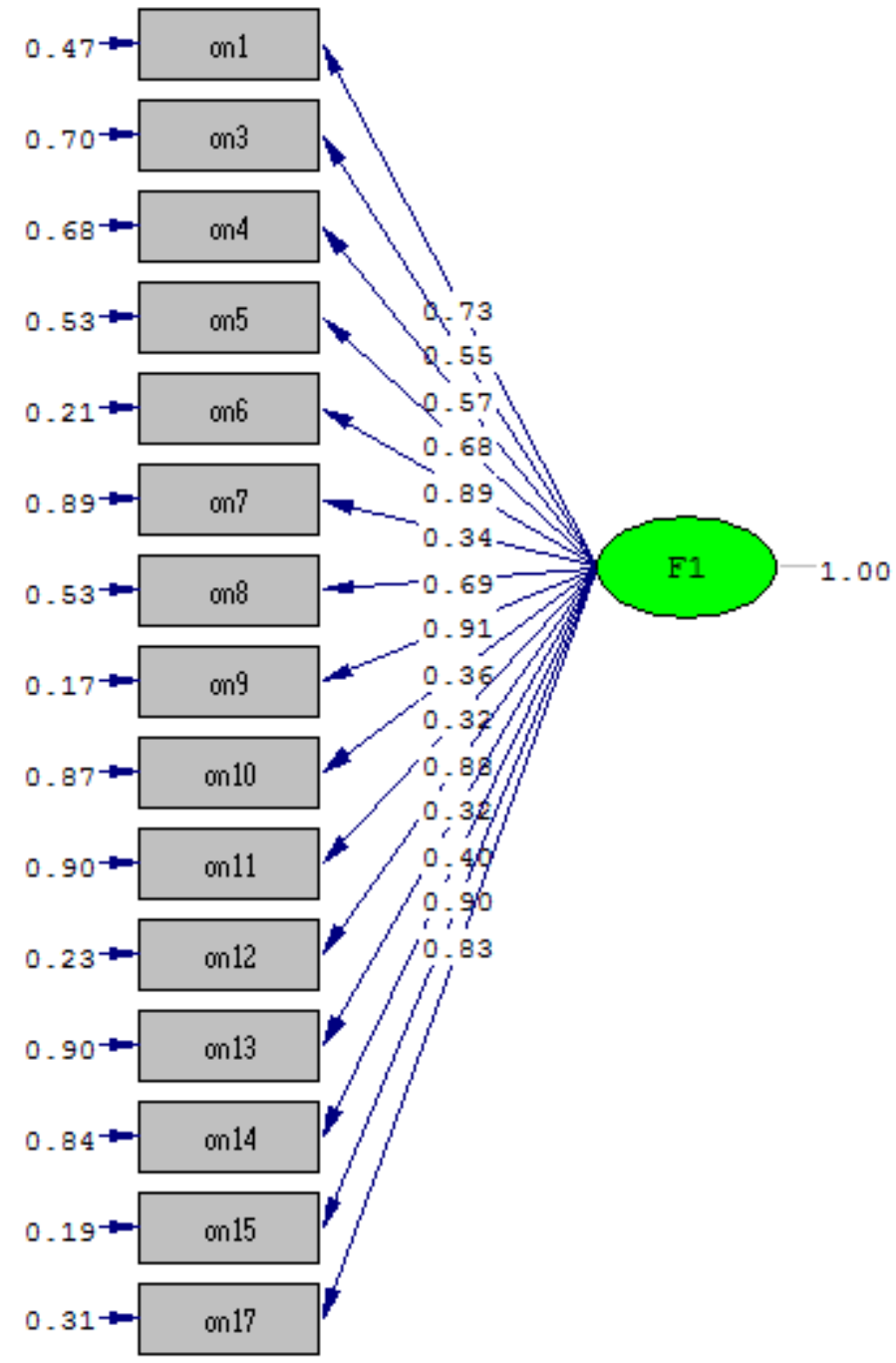

$$
\text { Chi-Square=182.99, df=90, P-value=0.00000, RMSEA=0.079 }
$$

Standardized factor loadings on the predictive factor is presented in Table 3. The factor loadings range between .32 and .91. According to Cohen and Lawrence (1989), factor loadings greater than .30 can be interpreted within factor analysis. In addition to that, error variances of item 7, 10, 11 and 13 are quite high. However, these items have significant t values in the model. Çokluk, Şekercioğlu and Büyüköztürk (2012) stated that in such a case, researchers may decide to include the items, for this reason, items were not excluded.

\subsection{Internal Consistency and Test-retest Reliability}

Internal consistency was calculated by examining cronbach alpha coefficients. The cronbach alpha coefficient was calculated through the study group consisting of 167 pre-school children and it is .91 which means the items have high consistency with each other.

Test-retest method was used examine the stability of ASK-R's results depending on the time. The test-retest reliability was examined through a sub-sample of the study group re-completing the scale three weeks after the first application. 
ASK-R was applied to 97 children twice and test-retest reliability coefficient was .78 after these processes. According to Tabachnick and Fidell (2001) the test-retest reliability assessment is indicative of good temporal stability.

\section{Discussion}

The purpose of this study is to examine the psychometric properties of the ASK-R for Turkish community sample. ASK-R is a practical assessment tool which is easy to understand, easily applicable and easy to rate in inclusive classroom settings by researchers, teachers and other professionals. It is short and application of the scale is not time consuming.

The results show that the Turkish version of ASK-R has good validity and reliability for Turkish pre-school children. ASK-r has been previously validated and used in different countries from Western (Boer, et.al., 2014; Nikolaraizi, et.al, 2005) and Eastern cultures (Oh, 2016). In this study, results are consistent with previous literature.

During the administration and analysis processes, 3 items were excluded from the scale. 2 of them were negatively formulated statements. Boer, et.al., (2014) also excluded 4 negatively formulated statements and reported that reliability analysis revealed (after recoding) these 4 items had low correlations with other items. Especially items 16 and 18, which we excluded, were challenging statements for children which is "Do you sometimes pick on (tease) kid who are different?" and "Are you sometimes mean to other kids?".

In the present study, confirmatory factor analysis applied to evaluate factor structure of the scale. One factor model was tested and model fit was acceptable as expected. Nikolaraizi et. al. (2005) also reported that they tested a one factor model and either their model fit was acceptable. Additionally, the internal consistency and test-retest reliability of ASK-R were satisfactory. These results are additional evidences for reliability and validity of the ASK-R. Nikolaraizi et. al. (2005) implied cronbach $\alpha$ level was .89 for Greek sample and .82 for US sample. Boer et. al. (2014) also stated that cronbach $\alpha$ level was .79 for Dutch sample. Turkish form of ASK-R has an internal consistency $(\alpha=.91)$ greater than other adaptation studies of ASK-R. As a result of the study, the Turkish version of ASK-R has good validity and reliability for community sample and the scale can be used confidently on pre-school children.

This study has limitations. First of all, our sample of children were limited and small. At first, more parents gave permission for test application but due to illness, absentia and other external factors, even less children participated in the study. Secondly, our sample was not randomized because of having problems about getting permission from school managers. Finally, our test application was made by university students. Although they all have related courses and have previous school experience they were not experienced test applicants.

In conclusion, acceptance in early childhood is important for successful inclusion of children with special needs. On the other hand, research in Turkey is limited because of the need for reliable and valid measures. These findings support the use of the ASK-r in Turkey, and open a door to additional research both on the ASK-r as a measure and on its use in early childhood intervention programs in Turkey.

\section{Acknowledgements}

We thank Research Project class students (Aslı ÇETINKAYA, Aylin ÖKSÜZ, Besra TEZKORKMAZ, Çiğdem Kübra TELTIK, Esra KURTULMUŞ, Esra PARALI, Fulya ÖZKAN, Funda Simge BAŞPINAR, Gül SÜRMELIOĞLU, Gülşah Zeynep SAYAR, Hasret AVŞAR, Hilal KARACAAĞAÇ, Irmak YALÇIN, Lale HOŞADAM, Münire Sinem ÜNAL, Neşe ÇAMBEL, Nuran SÖNMEZ, Rabia Cemre ARSLAN, Sabriye İNCEEL, Safure MARTOĞLU, Serkan DAĞLI, Şeyda ÖZKAN, Tuğçe KUÇET, Ümmühan TİLKİ) at Mugla Sitki Kocman University for their assistance with collecting this research data.

\section{References}

Aktaş, C., \& Küçüker, S. (2002). Bilişsel-duyuşsal odaklı bir programın ilköğretim öğrencilerinin fiziksel engelli yaşıtlarına yönelik sosyal kabul düzeylerine etkisinin incelenmesi. Özel Ĕ̆itim Dergisi, 3(2), 15-25.

Bossaert, G., Colpin, H., Pijl, S. J., \& Petry, K. (2013). Truly included? A literature study focusing on the social dimension of inclusion in education. International Journal of Inclusive Education, 17(1), 60-79. https://doi.org/10.1080/13603116.2011.580464

Buhs, E. S., \& Ladd, G. W. (2001). Peer rejection as antecedent of young children's school adjustment: An examination of mediating processes. Developmental Psychology, 37(4), 550. https://doi.org/10.1037/0012-1649.37.4.550

Cohen, L., \& M.Lawrence (1989). Manian Research Method in Education, New York: Routledge.

Çokluk, Ö., Şekercioğlu, G., \& Büyüköztürk, Ş. (2012). Sosyal Bilimler için Çok Değişkenli İstatistik SPSS ve LISREL Uygulamaları, Ankara: PegemA Yayıncilık.

de Boer, A., Pijl, S. J., Minnaert, A., \& Post, W. (2014). Evaluating the effectiveness of an intervention program to 
influence attitudes of students towards peers with disabilities. Journal of Autism and Developmental Disorders, 44(3), 572-583. https://doi.org/10.1007/s10803-013-1908-6

Diken, I. H., Bayban, P., Turan, F., Sipal, F., Sucuoglu, B., Ceber-Bakkaloglu, H. et al. (2012). Early childhood intervention and early childhood special education in Turkey within the scope of the developmental systems approach. Infants \& Young Children, 25, 346-353. https://doi.org/10.1097/IYC.0b013e318268541d

Diken, I. H., Rakap, S., Diken, O., Tomris, G., \& Celik, S. (2016). Early childhood inclusion in Turkey. Infants \& Young Children, 29(3), 231-238. https://doi.org/10.1097/IYC.0000000000000065

Favazza, P. C., Phillipsen, L., \& Kumar, P. (2000). Measuring and promoting acceptance of young children with disabilities. Exceptional Children, 66(4), 491-508. https://doi.org/10.1177/001440290006600404

Hooper, D., Coughlin, J., \& Mullen, M. R. (2008). Structural equation modeling: Guidelines for determining model fit. Electronic Journal of Business Research Methods, 6, 53-60.

Jöreskog, K. G., \& Sörbom, D. (1993). LISREL 8: Structural Equation Modeling with the SIMPLIS Command Language. Scientific Software International.

Ladd, G. W., Kochenderfer, B. J., \& Coleman, C. C. (1997). Classroom peer acceptance, friendship, and victimization: Destinct relation systems that contribute uniquely to children's school adjustment? Child Development, 68(6), 1181-1197. https://doi.org/10.2307/1132300

Metin, Ş. (2016). Türkiye'de okul öncesinde kaynaştırmaya ilişkin yapılan çalışmaların incelenmesi. Bayburt Eğitim Fakültesi Dergisi, 8(1), 146-172.

Nikolaraizi, M., Kumar, P., Favazza, P., Sideridis, G., Koulousiou, D., \& Riall, A. (2005). A cross-cultural examination of typically developing children's attitudes toward individuals with special needs. International Journal of Disability, Development and Education, 52(2), 101-119. https://doi.org/10.1080/10349120500086348

Odom, S. L. (2000). Preschool inclusion: What we know and where we go from here. Topics in Early Childhood Special Education, 20, 20-27. https://doi.org/10.1177/027112140002000104

Oh, H. W. (2016). Promoting acceptance of young children with special needs among preschoolers in Singapore (Doctoral dissertation).

Ostrosky, M. M., Mouzourou, C., Dorsey, E. A., Favazza, P. C., \& Leboeuf, L. M. (2015). Pick a book, any book: Using children's books to support positive attitudes toward peers with disabilities. Young Exceptional Children, 18(1), 30-43. https://doi.org/10.1177/1096250613512666

Şahbaz, Ü. (2007). Normal öğrencilerin kaynaştırma sınıflarına devam eden engelli öğrenciler hakkında bilgilendirilmelerinin engellilerin sosyal kabul düzeylerine etkisi. Eurasian Journal of Educational Research, 26, 199-208.

Tabachnick, B. G., Fidell, L. S., \& Osterlind, S. J. (2001). Using Multivariate Statistics. Needham Heights, MA: Allyn \& Bacon

Ullman, J. B. (2001). Structural equation modeling. In B.G. Tabachnick \& L.S. Fidell (2001). Using Multivariate Statistics (4th ed., pp. 653- 771). Needham Heights, MA: Allyn \& Bacon.

Vignes, C., Coley, N., Grandjean, H., Godeau, E., \& Arnaud, C. (2008). Measuring children's attitudes towards peers with disabilities: A review of instruments. Developmental Medicine \& Child Neurology, 50(3), 182-189. https://doi.org/10.1111/j.1469-8749.2008.02032.x

Vreeman, R. C., \& Carroll, A. E. (2007). A systematic review of school-based interventions to prevent bullying. Archives of Pediatrics \& Adolescent Medicine, 161(1), 78-88. https://doi.org/10.1001/archpedi.161.1.78

Yu, S., Ostrosky, M. M., \& Fowler, S. A. (2012). Measuring young children's attitudes toward peers with disabilities highlights from the research. Topics in Early Childhood Special Education, 32(3), 132-142. https://doi.org/10.1177/0271121412453175

\section{Copyrights}

Copyright for this article is retained by the author(s), with first publication rights granted to the journal.

This is an open-access article distributed under the terms and conditions of the Creative Commons Attribution license which permits unrestricted use, distribution, and reproduction in any medium, provided the original work is properly cited. 